\title{
POLA SPASIAL TERITORI PADA LANSKAP-HUNIAN MASYARAKAT PELADANG DESA JURUAN LAOK MADURA TIMUR
}

\author{
Redi Sigit Febrianto, Lisa Dwi Wulandari, Herry Santosa \\ Magister Arsitektur Lingkungan Binaan (ALB), Fakultas Teknik, Universitas Brawijaya \\ Email: advento6666@gmail.com
}

\begin{abstract}
Abstrak
Masyarakat etnis Madura dikenal sebagai masyarakat peladang jagung yang individual, mandiri dan berpola subsistensi, diidentifikasi memiliki tiga teritori utama yaitu: teritori hunian, teritori ruang terbuka dan teritori lanskap pertanian. Jarak antar cluster hunian berjauhan menyebabkan disebut sebagai masyarakat individual sekaligus mandiri. Ketergantungan hidup terhadap hasil panen menyebabkan jarak hunian dengan lanskap pertaniannya sangat dekat sehingga disebut masyarakat subsistensi. Moral ekonomi berorientasi pada tanah (land ethics),karena kegigihan mempertahankan spasial teritorinya. Sehingga pertanyaan mendasar penelitian adalah bagaimana pola spasial ketiga teritori pada desa Juruan Laok Madura? Strategi yang digunakan adalah etnografi, dengan rancangan penelitian kualitatif. Metode pengumpulan data utama berupa wawancara mendalam, tak-tik pertanyaan terbuka, dengan teknik sampling kasus tipikal pada empat hunian berdasarkan lima kriteria yaitu: civitas, aktivitas, pola hunian, pola lanskap pertanian dan eksistensi artefak berupa obyek penyimpanan panen. Validasi internal berupa observasi, pengukuran dan dokumentasi arsitektural, disebabkan sifat subsistensi etnis madura, sehingga kepala desa bukan nara sumber validasi internal, melainkan partisipan selaku pemilik hunian. Analisis dilakukan dengan mengkomparasi dengan konsep arsitektural-antropologis, konsep human space, juga dengan studi tema terkait. Hasil yang diperoleh adalah perwujudan konsep pola spasial yang disebut habitat. Konsep pola spasial yang disebut habitat ini terdiri dari : place, environment dan landscape. Susunan ketiganya membentuk satu gelembung hirarki yaitu place berada di dalam environment, sedangkan place dan environment berada di dalam landscape. Merujuk konsep dari arsitektural-antropologis, hirarki ketiga unsur ini disebut sebagai: habitat.
\end{abstract}

Kata kunci: teritori utama, eksistensi artefak arsitektural-antropologis dan habitat

\begin{abstract}
Title: The Spatial Pattern of Teritory on The Landscape-Dwelling Community Juruan Laok Village East Madura

The Madurese community is known as an individual, independent and subsistent corn farming community, identified as having three main territories: residential territory, open space territory and agricultural landscape territory. The distance between clusters of distant residential causes is referred to as individual society as well as independent. The dependence of life on crops causes the distance of dwelling with the agricultural landscape so close that it is called subsistence society. Land-based economic morality, due to the persistence of maintaining spatial territory. So the fundamental question of research is how the third spatial pattern of territory in the village of Laok Madura Madura? The strategy used is ethnography, with qualitative research design. The main data collection methods were in-depth interviews, no open questions, with typical case sampling techniques in four occupancy based on five criteria: civitas, activity, shelter pattern, agricultural landscape pattern and artifacts existence
\end{abstract}


of crop storage object. Internal validation in the form of observation, measurement and architectural documentation, caused by the characteristic of ethnic sub-ethnic of Madura, so that the head of village is not a source of internal validation, but the participant as the owner of the dwelling. The analysis is done by comparing with anthropological-architectural concept, human space concept, also with related theme study. The results obtained at least found the embodiment of the concept of spatial patterns called habitat. The concept of a spatial pattern called habitat consists of: place, environment and landscape. The arrangement of the three forms a hierarchical bubble that places in the environment, while place and environment are in the landscape. Referring to the concept of architectural-anthropological, the hierarchy of these three elements is referred to as: habitat.

Keywords: main territory, the existence of architectural-anthropological and habitat artifacts

\section{Pendahuluan}

\section{Fenomena Empiris}

Pekarangan (taneyan) dan teritori lanskap pertanian (klebun) (De Jonge, 1989; Febrianto et al., 2016; Ma'arif, 2015). Ketiga teritori utama tersebut dipisahkan oleh batas fisik teritori (berupa: peninggian tanah, beda material, pagar hidup dan pagar) maupun batas simbolik teritori (berupa: rasa malu, takut, sungkan dan suci) (Febrianto et al., 2016). Pada lingkup meso, perwujudan spasial berupa teritori hunian (omah tongghu) dan teritori lanskap pertanian berupa ladang jagung (klebun) merupakan bagian yang tak terpisahkan. Pada lingkup mikro perwujudan spasialnya berupa ruang penyimpanan jagung (jhuurung) dan ruang dapur (dheepor). Jagung adalah tanaman adaptif kultural yang tumbuh pada topografi dataran tinggi dan kering di Madura bagian timur (Hefni, 2008) sehingga mata pencaharian utama adalah sebagai petani ladang (peladang) jagung. Ditemukan tiga pendapat mengenai struktur mata pencaharian masyarakat Madura, yaitu: (1) berdasarkan wilayah kepulauan (Geertz, 1983), (2) berdasarkan etnis dominan (Nawiyanto, 2011), dan (3) berdasarkan topografi dan iklim (Hefni, 2008). Pendapat ketiga dari Hefni (2008) menyempurnakan dari kedua pendapat lainnya, yaitu dengan membagi Madura menjadi dua bagian berdasarkan iklim dan topografi. Wilayah Madura barat (Bangkalan dan Sampang) dengan topografi dataran rendah dan curah hujan relatif tinggi sehingga cocok ditanami padi, sedangkan wilayah Madura Timur (Pamekasan dan Sumenep) mempunyai topografi dataran tinggi berupa bukit kapur dan curah hujan rendah sehingga mempunyai kultur ekologi tegal. Tannahil (1973) dan Kittler \& Sucher (2008) menjelaskan tanaman pangan dan bahan pangan (food crops dan food stuff) dapat mempengaruhi perkembangan sejarah (Tannahil, dalam Nawiyanto, 2011) dan juga mempengaruhi perkembangan kultur, yaitu sebagai bentuk penanda diri, mempunyai fungsi simbolis-ritual dan membentuk identitas kultural kelompok (Kitller \& Sucher dalam Nawiyanto, 2011). Tanaman jagung adalah tanaman adaptif kultural yang tumbuh pada topografi dataran tinggi dan kering di Madura bagian timur, sehingga merasuk menjadi tata nilai (pandangan hidup) dan tata laku (cara hidup) dan dianggap sebagai identitas kultural etnis Madura. 
Beberapa bukti jagung sebagai identitas kultur etnis Madura adalah: masyarakat Madura disebut masyarakat konsumsi jagung atau maize eaters (De Jonge, 1989; Kuntowijoyo, 2002), jagung disebut dalam cerita rakyat Madura (Hatib dalam Nawiyanto, 2011 ; Imron dalam Nawiyanto, 2011); menjadi pepatah, peribahasa, saloka dan ungkapan tradisional Madura yaitu songosong lombung (Nawiyanto, 2011) dan memiliki pola lanskap agraris yang disebut ekologi tegal (Hefni, 2008). Masyarakat peladang madura adalah masyarakat subsistensi yaitu hasil lanskap agraris untuk dikonsumsi sendiri (Hefni, 2008; Nawiyanto, 2011). Hubungan teritori antar keluarga inti (nuclear family) sangat erat, sedangkan hubungan teritori antar tetangga bersifat renggang. Masyarakat etnik madura bersifat dualisme, yaitu sebagai masyarakat yang kukuh membawa adat sebagai masyarakat agraris jenis peladang (Maningtyas, 2013; Tulistyantoro, 2005), juga sebagai masyarakat muslim taat Madura kukuh membawa latar budaya Islam (Susanto, 2008; Syamsuddin, 2007).

\section{Kajian Pustaka}

Aspek spasial teritori sebagai salah satu aspek yang diteliti yaitu berfokus pada aspek spasial (spatial system), merujuk pada pemikiran Habraken (1978) dalam pengidentifikasian wujud arsitektur. Penelitian ini tidak berfokus pada sistem fisik (physical system) maupun sistem model atau tampilan (stylictic system) sebagai pemikiran Habraken (1978) dalam pengidentifikasian wujud arsitektur. Lingkup penelitian berfokus pada lingkup meso (spasial teritori), bukan lingkup makro (spasial permukiman), maupun lingkup mikro (spasial ruang). Aspek Spasial tidak hanya dibatasi batas berupa fisik-baik secara geometri maupun tiga dimensinamun juga dibatasi beradasarkan persepsi manusia, dibentuk berdasarkan nilai budaya manusia dan memiliki pengertian metaforik (Fathony et al., 2012). Pola spasial dipahami sebagai jenis topologi yang dilihat dalam tiga subtopologi merujuk pada filosofi Egenter (1992) terdiri dari: place, environment, dan landscape, ketiganya tersusun membentuk satu gelembung hirarki spasial yang memiliki pola yang disebut sebagai: habitat. Konsep habitat yaitu place berada di dalam environment, sedangkan place dan environment berada di dalam landscape. Hartiningsih (2008) yang mempunyai cara lain dalam pengkajian konsep spasial yaitu terdiri dari struktur spasial dan nilai spasial. Struktur spasialberkaitan dengan tema empiris terdiri atas: organisasi, orientasi, sirkulasi dan batas fisik, sedangkan nilai spasial berhubungan dengan tema sosial terdiri atas: ekonomi, hubungan antar penghuni, sistem kultural, sistem gender dan ekologi.

Mata pencaharian masyarakat Indonesia sebagai masyarakat agraris - atau meminjam istilah dari Boelaars yaitu pola-pola kebudayaan masyarakat Indonesia-terdiri atas empat jenis masyarakat yaitu: masyarakat petani sawah, petani ladang, masyarakat pesisir (bahari) dan masyarakat peramu (perantau) (Boelaars, 1984). Boelaars menambahkan bahwa mentalitas polapola kebudayaan masyarakat Indonesia-atau lebih dikenal sebagai pandangan hidup masyarakat agraristerdiri atas: pandangan hidup terhadap alam semesta, antar sesama dan alam baka. Pandangan hidup terhadap alam 
semesta yang berwujud: objek hunian terkait dengan lanskap pertanian (lanskap-hunian) sebagai bagian dari masyarakat agraris. Pandangan hidup terhadap antar sesama berwujud: objek hunian terkait dengan kekerabatan (hunian-kekerabatan) sebagai bagian dari masyarakat subsistensi yang madiri. Pandangan hidup terhadap alam baka berwujud: objek hunian terkait dengan kesakralan (hunian-kesakralan) sebagai bagian dari masyarakat muslim.

\section{Kajian Studi Terdahulu}

Kajian penelitian terdahulu sudah dibahas berdasarkan: (1) mata pencaharian, (2) pandangan hidup dan (3) lingkup penelitian. Kajian penelitian terdahulu yang menyebutkan konsep spasial hunian etnis Madura berdasarkan mata pencahariannya yaitu sebagai: pulau garam dengan masyarakat petani garam di pesisir pantai Madura dengan konsep wilayah garam (Citrayati et al., 2008; Wahid, 2015); sebagai masyarakat nelayan dengan konsep hunian takat lanjheng atau karang panjang di pesisir pantai Madura (Ma'arif, 2015); sebagai masyarakat peladang tembakau di Madura timur (De Jonge, 1989; Zamroni, 2007); sebagai masyarakat petani sawah di Madura barat dengan konsep budaya padi (Hefni, 2008; Nawiyanto, 2011); masyarakat peladang di Madura timur dengan konsep hunian berkelompok yang salah satunya dikenal sebagai taneyan lanjheng atau pekarangan panjang.

Kajian penelitian terdahulu sudah dibahas berdasarkan pandangan hidupnya yaitu: berdasarkan pandangan hidup terhadap antar sesama (huniankekerabatan) (Maningtyas, 2013; Tulistyantoro, 2005), berdasarkan pandangan hidup terhadap alam baka (hunian-kesakralan) (Susanto, 2008; Tulistyantoro, 2005; Wismantara, 2009). Pembahasan pandangan hidup terhadap antar sesama terutama pada masyarakat Madura perantau juga sudah sangat sering dibahas (Ardianti et al., 2014; Ari \& Antariksa, 2005; Asikin et al., 2016; Fathony et al., 2012; Fauzia et al., 2009; Sasongko, 2005; Tjahjono et al., 2011). Pada dasarnya penelitian spasial hunian berdasarkan lanskap pertaniannya (lanskap-hunian) sudah sering dibahas baik pada tema sosial maupun tema arsitektural. Penelitian sosial masyarakat peladang dari Hefni dan Nawiyanto lebih banyak membahas peran jagung dalam kehidupan sosial (Hefni, 2008; Nawiyanto, 2011), sedangkan penelitian dari Rochana membahas pengaruh lahan pertanian jagung terhadap sikap dan mentalitas (Rochana, 2012). Penelitian lanskap-hunian hanya dilakukan dua peneliti (Maningtyas, 2013; Tulistyantoro, 2005), namun tidak secara detail membahas pola spasialnya. Penelitian Tulistyantoro lebih banyak membahas hunian kekerabatan pada lingkup mikro namun tidak menyebutkan lokasi desa secara mendetail (Tulistyantoro, 2005). Penelitian Maningtyas membahas hunian-kekerabatan dan lanskap-hunian pada lingkup meso dan lingkup mikro di Desa Lenteng Timur (Maningtyas, 2013). Keduanya tidak menjelaskan pola spasial yang terbentuk pada lanskaphunian masyarakat peladang etnis Madura khususnya di Madura timur.

Kajian penelitian terdahulu sudah dibahas berdasarkan lingkupnya yaitu: penelitian terdahulu yang membahas etnis Madura tentang lingkup makro (permukiman) (Maningtyas, 2013; Tulistyantoro, 2005) dan penelitian terdahulu yang membahas etnis Madura 
tentang lingkup mikro (ruang) (Tulistyantoro, 2005; Wismantara, 2009). Namun penelitian terdahulu yang membahas etnis Madura tentang lingkup meso (teritori) masih jarang dilakukan.

\section{Permasalahan}

Penelitian ini berbeda dengan penelitian terdahulu, karena berfokus pada pola spasial teritori berdasarkan pandangan hidupnya terhadap alam semesta sebagai masyarakat peladang jagung terutama pada lingkup meso atau spasial teritori di Desa Juruan Laok, Kecamatan Batuputih, Kabupaten Sumenep, Madura timur. Desa Juruan Laok terpilih menjadi lokus penelitian karena enam kriteria yang didapat dari hasil wawancara, observasi, pengukuran dan dokumentasi lapangan tidak ditemukan pada desa lainnya , yaitu: (1) keragaman civitas (anak menetap hingga anak merantau); (2) keragaman aktivitas (aktivitas berladang hingga aktivitas nonberladang); (3) ragam pola hunian (pola mengelompok hingga pola mandiri); (4) ragam pola lanskap pertanian (lanskap mengelilingi hunian hingga lanskap sejajar hunian) dan (5) eksistensi artefak (aktif hingga pasif).

Sehingga penelitian ini tidak berfokus pada hunian masyarakat agraris jenis lain seperti masyarakat perantau, masyarakat petani sawah dan masyarakat pesisir, namun berfokus pada masyarakat peladang jagung di Madura timur. Penelitian ini juga tidak berfokus pada pandangan hidup terhadap antar sesama (hunian-kekerabatan) dan pandangan hidup terhadap alam baka (hunian-kesakralan), namun berfokus pada pandangan hidup terhadap alam semesta (lanskap-hunian). Penelitian ini juga tidak berfokus pada lingkup makro (permukiman) dan lingkup mikro (ruang), namun berfokus pada lingkup meso (teritori).

Pembahasan aspek spasial akan sangat luas dan mendalam. Oleh sebab itu fokus permasalahan akan dibatasi pada lingkup meso (teritori), dalam hal ini adalah bentuk pola spasial teritori lanskaphunian . Pertanyaan mendasar mengenai lanskap-hunian ini adalah bagaimana pola spasial teritori pada desa Juruan Laok Madura? Masyarakat peladang di Madura diidentifikasi memiliki pola yang terbentuk dari tiga teritori utama yaitu: teritori hunian, teritori ruang terbuka dan teritori lanskap pertanian. Penelitian ini berusaha memahami aspek pola spasial teritori pada obyek lanskaphunian. Hasil yang diperoleh setidaknya ditemukan bentuk pola spasial diantara ketiga teritori-pada lanskap-hunian masyarakat peladang Desa Juruan Laok_-yang disebut sebagai: habitat.

\section{Deskripsi Desa Juruan Laok}

Deskripsi Desa Juruan Laok sekaligus sebagai tahap pertama yaitu tahap pengumpulan data utama melalui wawancara mendalam melalui tak-tik pertanyaan terbuka dengan pengambilan sampel kasus tipikal (Patton, 1990 dalam Poerwandari, 2007). Pengumpulan data primer berupa wawancara, sedangkan observasi, pengukuran dan dokumentasi arsitektural bersifat validasi internal, sedangkan data sekunder hanya sebagai pelengkap. Validasi internal tidak melalui kepala desa karena kurang memiliki pengaruh dan bukan perantara kultural (cultural broker) yang utama (Zamroni, 2007).

Aspek penelitian berupa pola spasial teritori, sedangkan obyek penelitian teritori lanskap-pertanian pada masyarakat peladang Desa Juruan Laok 
di daerah yang disebut Lengga yang terletak di Kecamatan Batuputih, Kabupaten Sumenep, Madura timur. Berdasarkan topografinya Desa Juruan Laok terdiri dari tiga jenis wilayah, yaitu: wilayah pantai, wilayah dataran rendah dan wilayah dataran tinggi (BPS, 2016). Desa Juruan Laok merupakan desa dengan kondisi dataran rendah yang terletak 150 diatas permukaan laut (dpl) sehingga cocok digunakan sebagai area berladang terutama jagung yang tidak membutuhkan banyak air.

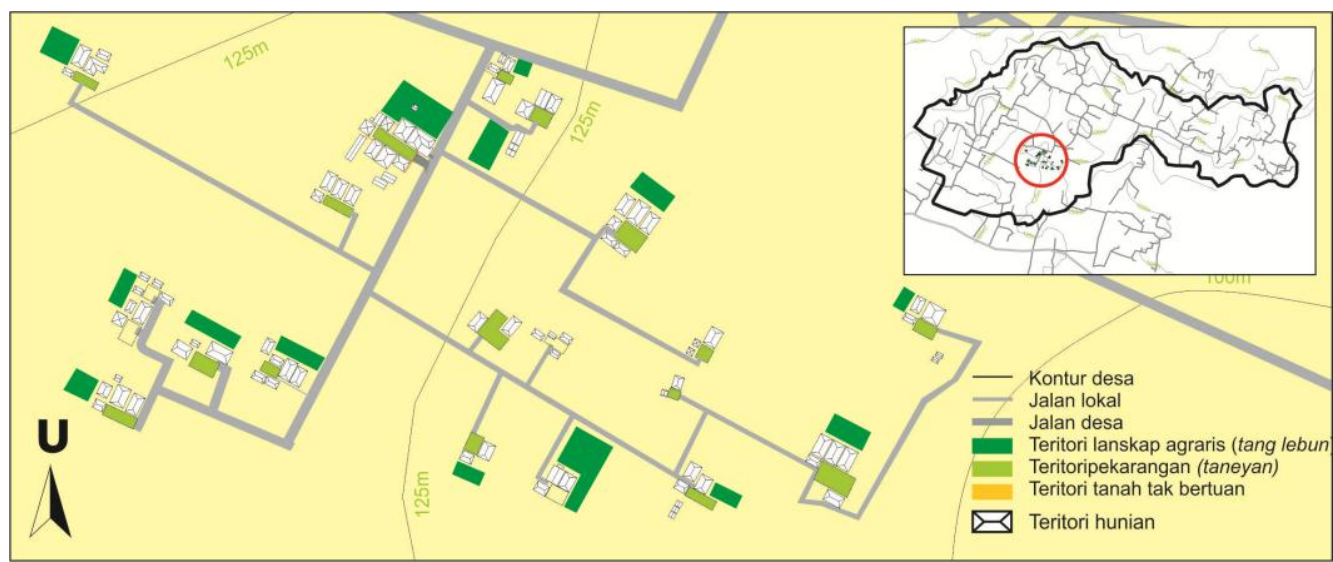

Gambar 1. Daerah Lengga di desa Juruan Laok (Lat: $0^{\circ}{ }^{55}{ }^{\prime} 01$ ” S, Lon: $113^{\circ} 58{ }^{\prime} 17^{\prime}$ E)

Sumber: https://earthexplorer.usgs.gov/ (diolah)

Pada tahap pengumpulan data diketahui diketahui sebanyak 520 kepala keluarga (KK) yang bergerak di bidang tanaman pangan (BPS, 2016) Beberapa masyarakat diluar populasi bermata pencaharian di bidang perkebunan sebanyak 8 kepala keluarga (KK), bidang peternakan sebanyak 27 kepala keluarga (KK). Berdasarkan batasan wilayah penelitian mempersempit dari 520 hunian menjadi 18 kasus hunian umum (populasi). Terdapat tiga kriteria batas wilayah penelitian yaitu berlokasi di sekitar daerah yang dinamakan Lengga terletak di Desa Juruan Laok, pada kontur dataran rendah dan hunian terletak jauh dari jalan utama.
Strategi penelitian etnografi memperbolehkan pengenal kajian pustaka dari studi terdahulu (masyarakat peladang di Madura) maupun studi terkait (masyarakat peladang diluar Madura) untuk dapat membentuk indikator kajian pustaka sebagai gambaran fokus penelitian (Creswell, 2010). Indikator kajian pustaka merujuk pada Rapoport (1982) dan Hillier (1989) yaitu: (1) civitas, (2) aktivitas, dan (3) ruang (setting) berupa pola hunian dan pola lanskap pertanian dan (4) artefak (Hillier, 1989; Rapoport, 1982).

Pada tahap pengumpulan data diketahui diketahui sebanyak 520 kepala keluarga (KK) yang bergerak di bidang tanaman 
pangan (BPS, 2016) Beberapa masyarakat diluar populasi bermata pencaharian di bidang perkebunan sebanyak 8 kepala keluarga (KK), bidang peternakan sebanyak 27 kepala keluarga (KK). Berdasarkan batasan wilayah penelitian mempersempit dari 520 hunian menjadi 18 kasus hunian umum (populasi). Terdapat tiga kriteria batas wilayah penelitian yaitu berlokasi di sekitar daerah yang dinamakan Lengga terletak di Desa Juruan Laok, pada kontur dataran rendah dan hunian terletak jauh dari jalan utama.
Strategi penelitian etnografi memperbolehkan pengenal kajian pustaka dari studi terdahulu (masyarakat peladang di Madura) maupun studi terkait (masyarakat peladang diluar Madura) untuk dapat membentuk indikator kajian pustaka sebagai gambaran fokus penelitian (Creswell, 2010). Indikator kajian pustaka merujuk pada Rapoport (1982) dan Hillier (1989) yaitu: (1) civitas, (2) aktivitas, dan (3) ruang (setting) berupa pola hunian dan pola lanskap pertanian dan (4) artefak (Hillier, 1989; Rapoport, 1982).

Tabel 1. Kriteria kasus studi hunian terpili (sampel) sekaligus indikator

\begin{tabular}{|c|c|c|c|c|c|}
\hline \multirow{2}{*}{$\begin{array}{c}\text { No } \\
\text { Kasus } \\
\text { Hunian }\end{array}$} & \multicolumn{2}{|l|}{ Subyek Penelitian } & \multicolumn{3}{|c|}{ Obyek Penelitian } \\
\hline & Civitas & Aktivitas & Pola hunian & $\begin{array}{l}\text { Pola lanskap } \\
\text { pertanian }\end{array}$ & $\begin{array}{l}\text { Eksistensi } \\
\text { Artefak }\end{array}$ \\
\hline 1 & $\begin{array}{c}\text { menikah } \mid \text { peladang } \mid \text { 3anak } \mid \\
\text { berkumpul }\end{array}$ & peladang & $\begin{array}{c}\text { pola hunian } \\
\text { mengelompok (tiga } \\
\text { generasi hunian) }\end{array}$ & $\begin{array}{l}\text { Pola pertanian } \\
\text { sejajar hunian }\end{array}$ & Artefak Aktif \\
\hline 2 & $\underset{\text { merantau }}{\operatorname{menikah} \mid \text { peladang } \mid \text { lanak } \mid}$ & peladang & pola indenpenden & $\begin{array}{l}\text { Pola pertanian } \\
\text { mengelilingi } \\
\text { hunian }\end{array}$ & Artefak Pasif \\
\hline 3 & 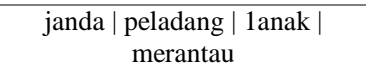 & peladang & pola indenpenden & $\begin{array}{l}\text { Pola pertanian } \\
\text { sejajar hunian }\end{array}$ & Artefak Aktif \\
\hline 4 & $\begin{array}{l}\text { Belum menikah | non-peladang } \\
\text { | belum punya anak }\end{array}$ & $\begin{array}{c}\text { non } \\
\text { peladang }\end{array}$ & $\begin{array}{c}\text { pola hunian } \\
\text { mengelompok (dua } \\
\text { generasi hunian) }\end{array}$ & $\begin{array}{l}\text { Tidak memiliki } \\
\text { lanskap pertanian }\end{array}$ & $\begin{array}{l}\text { Artefak } \\
\text { Negatif }\end{array}$ \\
\hline
\end{tabular}

Sumber: Wawancara lapangan (2017)

Sehingga batasan subyek penelitian adalah: (1) Memiliki derajat civitas (merantau-menetap); (2) Memiliki derajat aktivitas (peladang - non peladang), sedangkan batas obyek penelitian adalah: (3) pola hunian (berkelompok-mandiri), (4) pola lanskap (sejajar hunian - mengelilingi hunian) (5) Memiliki tempat penyimpanan panen sebagai artefak aktif. Batasan subyek penelitian dan batasan obyek penelitian adalah kriteria penentuan kasus hunian terpilih sekaligus indikator. Pada tahap identifikasi ini kriteria berfungsi mempersempit dari 18 kasus hunian umum (populasi) menjadi empat kasus hunian terpilih (sampel).

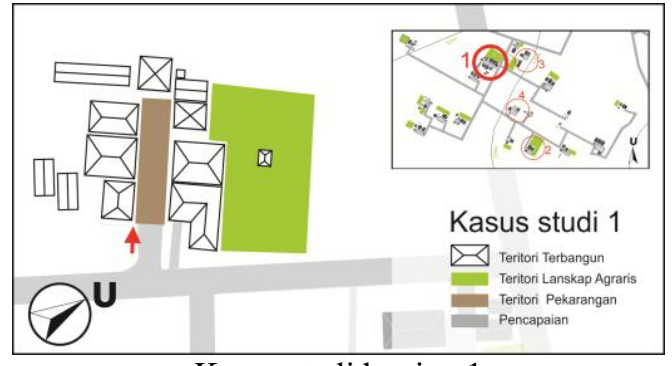

Kasus studi hunian 1

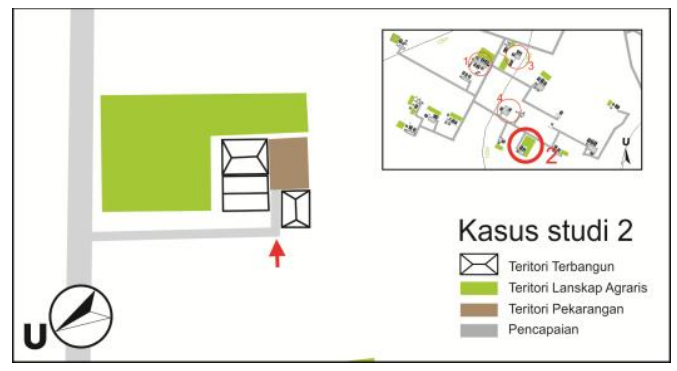

Kasus studi hunian 2 


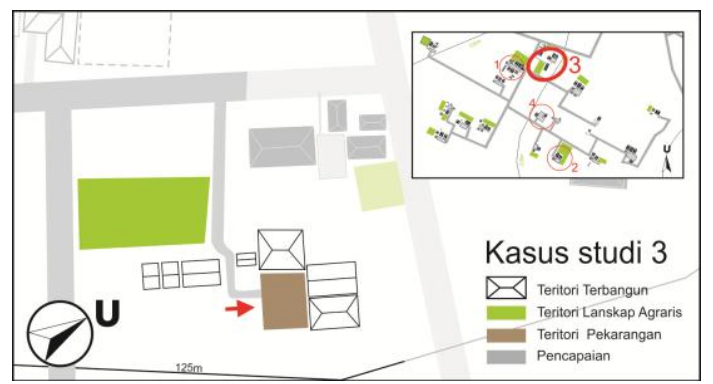

Kasus studi hunian 3

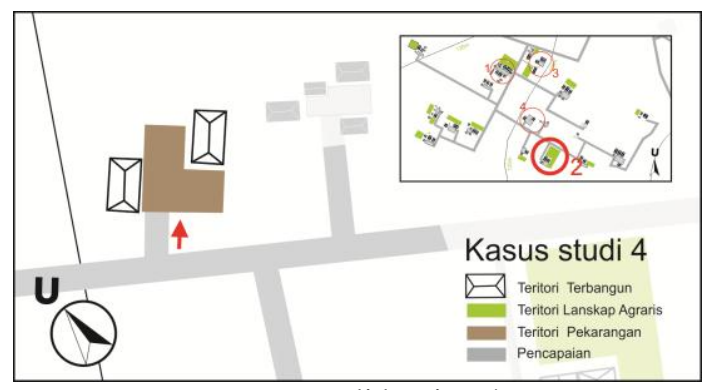

Kasus studi hunian 4

Gambar 2. Kasus studi hunian terpilih 1, 2, 3, 4 (sampel)

Sumber: Analisis penulis (2017)

\section{Tahap Identifikasi Data}

Tahap kedua adalah Tahap identifikasi yaitu menemukan indikator menggunakan analisis tematik (Boyatzis dalam Poerwandari, 2007) berdasarkan pemahaman partisipan, terdiri dari identifikasi awal (seeing) dan identifikasi lanjutan (seeing as). Analisis tematik memungkinkan peneliti menemukan (seeing) pola yang pihak lain tidak melihatnya secara jelas. Analisis lanjutan berusaha mengkoding

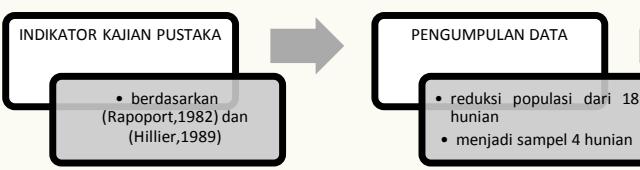

Gambar 3. Tahap metode penelitian

Sumber: (Poerwandari, 2007) diolah pola tersebut (seeing as) dengan memberi label, definisi atau deskripsi. Indikator kajian pustaka merujuk pada Rapoport (1982) dan Hillier (1989) yaitu: civitas, aktivitas, dan ruang (setting) berupa pola hunian dan pola lanskap pertanian dan artefak (Hillier, 1989; Rapoport, 1982). Sedangkan indikator dari hasil identifikasi dengan analisis tematik adalah: (1) anak menetap - anak merantau; (2) peladang - non peladang, (3) pola hunian mengelompok - pola hunian mandiri, (4) pola sejajar hunian - pola mengelilingi hunian dan (5) ruang penyimpanan panen aktif sering dipergunakan - pasif jarang digunakan. Setelah identifikasi awal berupa menemukan pola berupa indikator (seeing), dilanjutkan identifikasi lanjutan yaitu mengkoding indikator dari pola-pola tersebut (seeing as) menjadi sebuah tema-tema, yaitu: (a) civitas (anak menetap atau anak merantau); (b) aktivitas (aktivitas peladang atau non peladang); (c) pola hunian (hunian mengelompok atau mandiri); (d) pola lanskap pertanian (pola sejajar atau mengelilingi hunian dan (e) eksistensi artefak berupa ruang penyimpanan panen (jhuurung) (aktif, sering dipergunakan atau pasif, jarang digunakan). 
Identifikasi civitas dari hasil wawancara didasarkan pada pertanyaan umum terbuka yang diajukan pada desain survei penelitian yaitu: Siapa saja penghuni di rumah ini? Hasil identifikasi ditemukan bahwa kasus hunian 1,2,3 nara sumbernya adalah wanita, sudah menikah dan punya anak. Berbeda dengan sampel 4 adalah narasumbernya adalah pria, belum menikah. Sekilas dapat diketahui bahwa hunian bagi sampel yang sudah menikah dan anakanaknya menetap dalam cluster hunian induk mempunyai tatanan pola hunian mengumpul atau mengelompok yang sering disebut taneyan lanjheng. Berbeda lagi apabila bagi sampel yang sudah menikah dan anaknya hanya satu dan merantau pola huniannya adalah independen. Etnis Madura mengenal dua jenis pola hunian yaitu pola hunian mengelompok dan independen. Disebut taneyan lanjheng jika dihuni oleh empat sampai lima generasi penghuni, disebut koren jika dihuni oleh empat generasi penghuni dan disebut pamengkang jika dihuni oleh tiga generasi penghuni. Sedangkan disebut kampung meiji jika letak desa di daerah terpencil dihuni oleh lebih dari lima penghuni di daerah pelosok, terpencil dan jauh dari jalan utama (Amin et al., 2016). Desa Juruan Laok cukup unik karena merupakan gabungan dari dua jenis tatanan pola hunian yang umumnya ada di desa tersebut yaitu: pola hunian tiga generasi (pamengkang) pola hunian independen. Identifikasi aktivitas dari hasil wawancara didasarkan pada pertanyaan umum terbuka yang diajukan pada desain survei penelitian yaitu: bagaimana aktivitas keseharian masyarakat di desa ini? Hasil identifikasi ditemukan bahwa kasus hunian 1,2,3 aktivitas utamanya adalah sebagai peladang. Masyarakat peladang bersifat subsistensi yaitu hasil panen dikonsumsi sendiri, sehingga teritori hunian berada dekat dengan teritori lanskap pertanian. Pada kasus hunian 4 aktivitasnya adalah sebagai non peladang. Aktivitas terkait erat dengan civitas yaitu apabila keberadaan anak menetap di rumah orang tua, aktivitas anak adalah berladang, apabila keberadaan anak merantau aktivitas anak adalah berdagang.

Identifikasi artefak berdasarkan hasil wawancara didasarkan pada pertanyaan umum terbuka yang diajukan pada desain survei penelitian yaitu: area mana yang paling penting di rumah ini dan mengapa dianggap penting? Hasil identifikasi dari wawancara, observasi, pengukuran dan dokumentasi arsitektural pada kasus studi hunian 1,2,3 ditemukan ruang penyimpanan panen (jhuurung) dan ruang dapur (dheepor) sebagai teritori penyimpanan dan pengolahan panen. Pertanyaan umum terbuka yang diajukan pada desain survei penelitian adalah: Jawaban dari tiga nara sumber dari yaitu kasus studi hunian 1,2,3 yang menyebutkan bahwa: ruang-tempat penyimpanan panen (jhuurung) dan dapur (dheepor) sebagai ruang yang paling penting. Berbeda dengan sampel hunian ke-4 yang tidak memiliki ladang, belum menikah dan tidak mempunyai anak, ruang yang paling utama adalah ruang bilik tidur. Jhuurung dan dheepor dianggap penting karena untuk memenuhi kebutuhan pangan karena sifat dasarnya sebagai masyarakat subsistensi yaitu hasil panen untuk dikonsumsi sendiri.

Jhuurung adalah tempat penyimpanan jagung yang terletak pada ruang dapur dan terikat erat dengan tungku untuk 
memasak. Pada tiga dari empat kasus hunian terpilih (sampel) jhuurung selalu terletak diatas tungku, yang berguna untuk mengasapi jagung agar tidak dimakan serangga dan tidak cepat busuk. Adapun rangkaian proses jagung sebelum masuk ke dalam jhuurung adalah: setelah diambil dari tegal, dijemur di pekarangan (taneyan), diletakkan dalam tempat penyimpanan panen sementara (bhuudeg), dijemur lagi, setelah benar-benar kering baru diletakkan di dalam ruang-tempat penyimpanan panen permanen (jhuurung). Beberapa hunian tidak memiliki tempat penyimpanan permanen (jhuurung), namun memiliki tempat penyimpanan panen sementara (bhuudeg). Sehingga jhuurung dan bhuudeg yang selalu terletak di ruangan dapur (dheepor) dianggap sebagai ruangan yang paling penting dibandingkan dengan ruangan lain pada hunian masyarakat peladang. Hasil identifikasi ditemukan bahwa ruang yang paling penting pada hunian masyarakat peladang adalah ruang penyimpanan panen sedangkan ruang yang cukup penting adalah ruang bilik tidur

Identifikasi teritori hunian berdasarkan hasil wawancara, observasi, pengukuran dan dokumentasi arsitektural ditemukan pada kasus studi hunian 1 dan 4 pola huniannya berbentuk mengelompok, sedangkan pada kasus studi hunian 2 dan 3 pola huniannya berbentuk independen. Hunian masyarakat etnis Madura. Pola hunian masyarakat etnis Madura terdiri atas dua yaitu hunian berkelompok dan hunian independen. Banyak yang menganggap hunian berkelompok dalam satu cluster dikenal dengan nama taneyan lanjheng. Perlu diketahui bahwa akan disebut taneyan lanjheng jika dihuni oleh empat sampai lima generasi penghuni, disebut koren jika dihuni oleh empat generasi penghuni dan disebut pamengkang jika dihuni oleh tiga generasi penghuni. Sedangkan disebut kampung meiji jika letak desa di daerah terpencil dihuni oleh lebih dari lima penghuni di daerah pelosok, terpencil dan jauh dari jalan utama (Amin et al., 2016). Berdasarkan hasil wawancara diidentifikasi vahwa hirarki fungsi ruangnya, teritori hunian dikategorikan sebagai teritori yang cukup penting (sekunder) namun bukan yang paling penting (primer). Fungsi teritori primer mewujud pada unit bangunan penyimpanan dan pengolahan panan yang didalamnya terdapat ruang penyimpanan panen (jhuurung) dan ruang pengolahan panen atau biasa disebut dapur (dheepor). Sedangkan fungsi teritori sekunder mewujud pada unit bangunan hunian yang terdiri atas bilik ruang tidur dan ruang tengah. Anggapan bahwa ruang primer setara dengan ruang privat tidak berlaku pada hunian masyarakat peladang. Berdasarkan fungsinya ruang primer berbentuk ruang penyimpanan panen (jhuurung) dan ruang dapur (dheepor), sedangkan jika dilihat dari privasinya, ruang privat berbentuk ruang bilik tidur, sedangkan ruang intim yang menempati hirarki tertinggi berbentuk obyek penyimpanan panen dan dapur

Identifikasi teritori area terbuka berdasarkan hasil wawancara, observasi, pengukuran dan dokumentasi arsitektural ditemukan bahwa pada kasus studi hunian 1,2,3 ditemukan pekarangan (taneyan) sebagai ruang bersama untuk berkumpul. Pada area pekarangan dan ladang juga beberapa jenis tanaman untuk kebutuhan substensi, seperti sayur-mayur,buah, 
bunga, rempah, tali-temali, minyak. Pekarangan (taneyan) mengandung banyak fungsi yaitu: fungsi agraris, fungsi keseharian dan fungsi sosial.

Identifikasi lanskap pertanian berdasarkan hasil wawancara, observasi, pengukuran dan dokumentasi arsitektural ditemukan bahwa pada kasus studi hunian 1,2,3 ditemukan bahwa lanskap pertanian berupa ladang jagung. Sedangkan pada kasus studi hunian 4, tidak ditemukan lanskap pertanian karena mata pencahariannya bulan peladang. Masyarakat etnis Madura dikenal sebagai masyarakat peladang jagung yang individual, mandiri dan berpola subsistensi. Disebut individual dan mandiri karena sangat menggantungkan hidupnya pada hasil panen, tidak terikat sosial dan berpola subsistensi karena panen untuk dikonsumsi sendiri. Akibatnya hubungan teritori antar keluarga inti erat, sedangkan hubungan teritori antar tetangga renggang. Masyarakat peladang di Madura timur diidentifikasi menganut moral ekonomi yang berorientasi pada tanah (land ethics), sedangkan Madura perantau berorientasi pada pekerjaan (labour ethics). Konsep carok bagi Madura perantauan dengan moral labour ethics akan terjadi jika mata pencahariannya diganggu, namun bagi masyarakat Madura peladang dengan moral land ethics konsep carok akan terjadi jika teritorinya dimasuki tanpa ijin.

\section{Hasil dan Pembahasan}

\section{Civitas, Aktivitas dan Artefak}

Kajian mengenai unsur pembentuk spasial sudah dikaji oleh Purbadi (2010) dengan cara mengkomparasikan dengan konsep dari tiga pakar yaitu Rapoport (1977), Hillier (1989) dan Madanipur (1986). Rapoport menyebutkan bahwa spasial (socio spatial) terbentuk dan dibentuk oleh manusia dan benda (Rapoport, 1977), sedangkan Hillier menyebutkan spasial (spatial culture) terbentuk dan dibentuk karena manusia, sehingga menghasilkan artefak sebagai hasil aktivitas manusia (Hillier, 1989). Sedikit berbeda dengan Madanipour yang menyatakan bahwa spasial (socio spatial) terbentuk dan dibentuk karena manusia, obyek dan kejadian (Madanipour, 1996). Persamaan pada dialog ini adalah manusia adalah kunci dari terbentuknya spasial.

Berdasarkan hasil wawancarakemudian divalidasi dengan observasi, pengukuran dan dokumentasi arsitektural - ditemukan artefak berupa ruang-tempat penyimpanan hasil panen jagung disebut jhuurung. Ruang-tempat penyimpanan panen jagung yang disebut jhuurung dapat dianggap artefak sebagai salah satu kategorisasi penelitian etnografi dan sebagai perwujudan peradaban etnis Madura sebagai masyarakat agrikultur jenis peladang jagung di Madura timur. Terdapat dua contoh pada dua pulau yang berbeda mengenai ruang-tempat penyimpanan panen yaitu: pada masyarakat agrikultur berjenis masyarakat petani sawah pada komunitas Ciptagelar-Jawa barat, ruangtempat menyimpan panen berupa padi disebut lumbung yaitu perwujudan artefak peradaban konsep budaya padi (rice culture) (Kusdiwanggo, 2011, 2012), sedangkan pada suku Talang Mamak-Riau ruang-tempat menyimpan padi disebut rangkiang padi. Sehingga dapat disimpulkan bahwa ruang-tempat penyimpanan panen yang masih aktif digunakan dapat dikategorikan sebagai 
artefak (agriculture vernacular

architecture) (Kusdiwanggo, 2011).


Gambar 4. Alur pemikiran unsur sosial pembentuk spasial teritori: (a) Rapoport (1977); (b) Hillier (1989); (c) Madanipour (1986)

Sumber: (Purbadi, 2010)

Masyarakat etnis madura bersifat dualisme, yaitu sebagai masyarakat yang kukuh membawa adat tradisional sebagai masyarakat agraris jenis peladang (Maningtyas, 2013; Tulistyantoro, 2005), juga sebagai masyarakat muslim taat Madura kukuh membawa latar budaya Islam (Susanto, 2008; Syamsuddin, 2007). Kehidupannya berorientasi pada fungsi agraris untuk memenuhi kebutuhan hidup. Sebagai masyarakat peladang, tata nilai masyarakat peladang etnis madura hanya menghargai obyek penyimpanan panen (jhuurung) sebagai ruang dengan fungsi primer (utama), namun sebagai masyarakat muslim yang taat, mereka tidak menganggap jhuurung sebagai ruang yang bermakna sakral (suci) sehingga tidak memiliki nilai mistis, simbolis, medis maupun terapeutis (Febrianto et al., 2016).

Adapun unsur pembentuk spasial secara umum dapat dideskripsikan terdiri dari manusia sebagai subyek pelaku (civitas) terkait erat dengan mata pencahariannya (aktvitas), juga terkait dengan benda (Rapoport, 1977) atau artefak (Hillier, 1989) atau obyek-kejadian (Madanipour, 1996). Berdasarkan interpretasi peneliti, analisis lebih merujuk pada pemikiran Hillier (1989) karena menyebutkan artefak sebagai kategorisasi penelitian etnografi dan sebagai perwujudan peradaban etnis Madura. Sehingga berdasarkan analisis dapat disimpulkan bahwa spasial lanskap-hunian etnis madura di desa Juruan Laok terbentuk dari: masyarakat peladang (civitas) yang mata pencahariannya sebagai petani jagung (aktivitas), sehingga membentuk hasil peradaban civitas dan aktivitas berupa ruang penyimpanan jagung yang disebut jhuurung dan dikategorikan sebagai artefak (agriculture vernacular architecture).

\section{Teritori Hunian, Ruang Terbuka dan Lanskap}

Hasil identifikasi menyebutkan bahwa permukiman masyarakat peladang di Madura terdiri atas tiga teritori yaitu: teritori hunian berupa unit bangunan rumah (omah tongghu), teritori area terbuka berupa area pekarangan (taneyan) dan lanskap pertanian (klebun) yang dihubungkan oleh jalan lokal sebagai akses pencapaian. Berdasakan konsep dari Bollnow (1963 \& 2011), konsep ruang manusia (human space) terdiri atas tiga domain yaitu: badan, rumah, dan ruang terbuka (Bollnow, $1963 \&$ 2011). Konsep ruang antropologis-arsitektur Egenter (1992) 
terdiri dari tiga jenis topologis yaitu place, environment, dan landscape (Egenter, 1992).
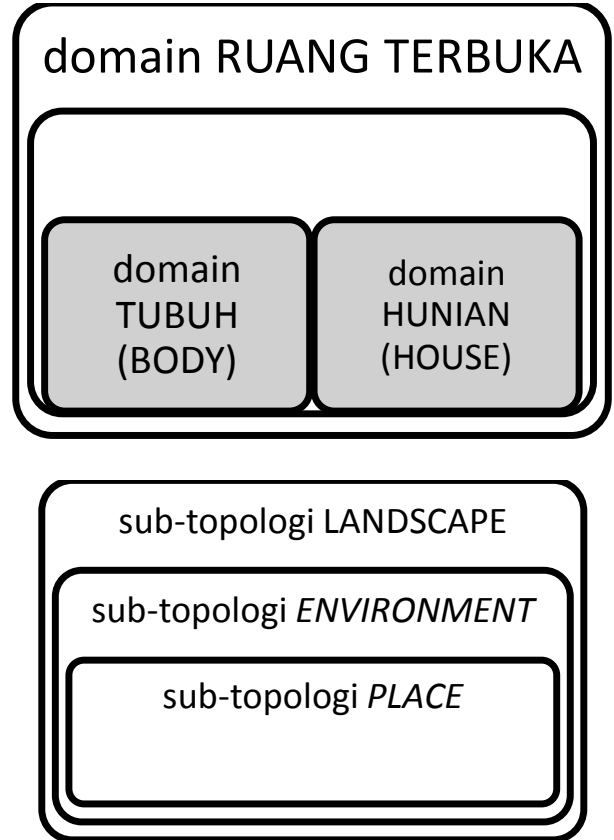

Gambar 5. Alur pemikiran unsur sosial pembentuk spasial teritori: (a) Bollnow (1963 \& 2011), (b) Egenter (1992)

Sumber: Bollnow dalam Kusdiwanggo (2012) dan Egenter dalam Kusdiwanggo (2012)

Pada domain badan terdiri atas unsur sosial pembentuk spasial yaitu: civitas sebagai masyarakat peladadang, aktivitas sebagai petani peladang dan artefak sebagai perwujudan peradaban masyarakat peladang. Domain badan bersanding dengan domain hunian sebagai unsur yang saling melengkapi. Jhuurung termasuk dalam kategori topologi tempat (place), domain tubuh sebagai artefak, dan juga sebagai bagian ruang dari domain hunian (house). Sehingga dapat disimpulkan bahwa konsep ruang manusia (human space) dari Bollnow (1963 \& 2011), terdiri atas tiga domain yaitu: domain badan (civitas sebagai masyarakat peladang, aktivitas sebagai petani peladang dan artefak berupa ruang-tempat penyimpanan panen), domain rumah (omah tongghu), dan domain ruang terbuka (taneyan). Konsep ruang antropologis-arsitektur Egenter (1992) terdiri dari tiga jenis topologis yaitu place (terdiri atas domain tubuh dan domain hunian), environment (teritori ruang terbuka berupa area pekarangan), dan landscape (teritori lanskap pertanian berupa area ladang jagung).

Berdasarkan identifikasi indikator terbentuk tema-tema, hasil analisis tematema kemudian terbentuk dua kategori merujuk pada konsep dari Hartiningsih (2008) yaitu: Struktur spasial dan Nilai spasial. Kategori struktur spasial berkaitan dengan tema-tema empiris, sedangkan kategori nilai spasial berkaitan dengan nilai-nilai sosial.

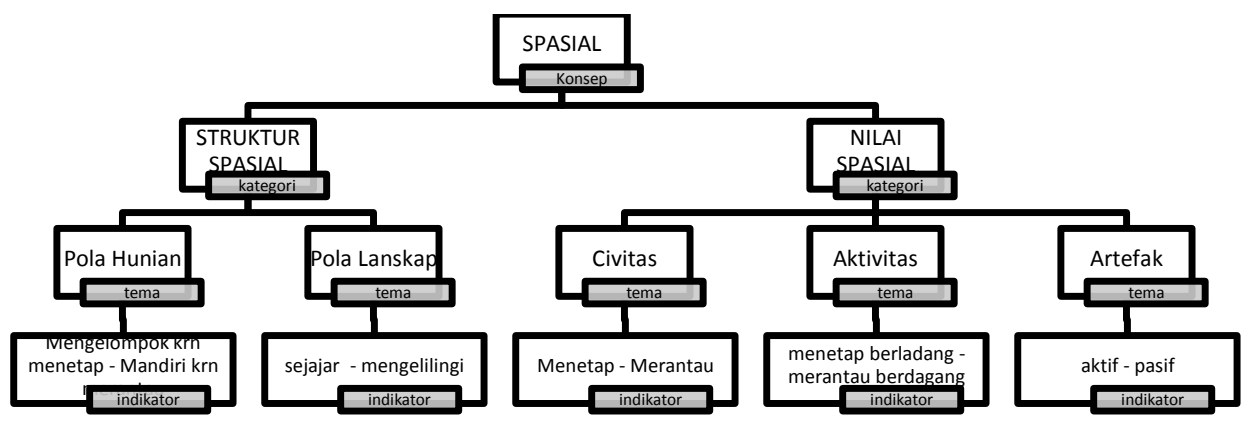

Gambar 6. Kerangka teori unsur-unsur pembentuk spasial Sumber: Analisis penulis (2017) 



\section{Pembahasan}

Sub-topologi pertama yaitu place (tempat) terdiri dari domain badan dan domain hunian. Pada domain badan terdapat tema sosial pembentuk spasial yaitu: civitas, aktivitas dan artefak. Sedangkan sub-topologi kedua yaitu environment (tapak) terdiri dari teritori ruang terbuka yaitu unit pekarangan (taneyan). Sedangkan konsep ketiga yaitu landscape terdiri dari teritori lanskap pertanian (ladang jagung/tegal). Ketigannya tersusun membentuk satu gelembung hirarki di mana place, berada di dalam environment; sedangkan place dan environment berada di dalam landscape.

Berdasarkan hasil sintesis diketahui bahwa konsep spasial terdiri dari dua kategori utama yaitu struktur spasial dan nilai spasial. Nilai spasial berkaitan dengan tema sosial sebagai unsur pembentuk, sedangkan struktur spasial berkaitan dengan tema empiris. Nilai spasial terdiri atas domain badan dan domai hunian yang terbentuk dalam gelembung awal disebut sub-topologi place (tempat), sedangkan domain ruang terbuka dan sub-topologi place terbentuk dalam gelembung kedua disebut subtopologi environtment (tapak). Subtopologi terakhir yang menaungi gelembung sebelumnya disebut subtopologi landscape (lanskap) terdiri dari domain landscape dengan sub-topologi environment. Ketiga subtipo-topologis disebut sebagai habitat yang terbentuk dari pola spasial teritori lanskap-hunian masyarakat peladang desa Juruan Laok.

Pada ketiga kedua dilakukan analisis lanjutan menggunakan teknik flip-flop yaitu dibandingkan dengan penelitian terdahulu pada kutub berlawanan yaitu tentang pola lanskap non-peladang berlokasi di luar Madura. Dengan menggunakan analisis teknik flip-flop pada langkah kedua, dapat diketahui perbedaan masyarakat peladang etnis madura dengan masyarakat agraris jenis lain diluar Madura. Sebagai komparasi diambil beberapa contoh masyarakat agraris dari kutub yang berlawanan selain masyarakat peladang dan lokasinya berada di luar Madura, beberapa diantaranya yaitu: (a) pola lanskap agraris masyarakat petani padi pada komunitas Ciptagelar (Kusdiwanggo, 2012); (b) pola lanskap agraris masyarakat peladang \& petani padi muslim Desa $\mathrm{Hu} u$ Flores (Syafrudin, 2009); (c) pola lanskap agraris masyarakat peladang Suku Dayak Benuaq (Ridjal, 2015).

Pada masyarakat petani padi pada komunitas Ciptagelar pola permukimannya berbentuk mengelompok, namun posisi teritori lanskap agrarisnya terletak terpisah dengan teritori huniannya (Kusdiwanggo, 2012). Teritori lanskap agraris berupa kebun, sawah dan kolam terletak di kawasan luar yang menurut kosmografi Sunda berada di dunia bawah. Namun teritori hunian berupa masjid, balai pertemuan dan hunian merupakan kawasan permukiman yang menurut kosmografi Sunda berada di dunia tengah. Sedangkan dunia atas berupa hutan keramat dan makam leluhur. Sama halnya dengan masyarakat peladang sekaligus petani sawah muslim Desa Hu'u di Flores (Syafrudin, 2009) dan masyarakat peladang Suku Dayak Benuaq (Ridjal, 2015), pola permukimannya berbentuk mengelompok namun posisi teritori lanskap agrarisnya terletak terpisah dengan teritori huniannya. 



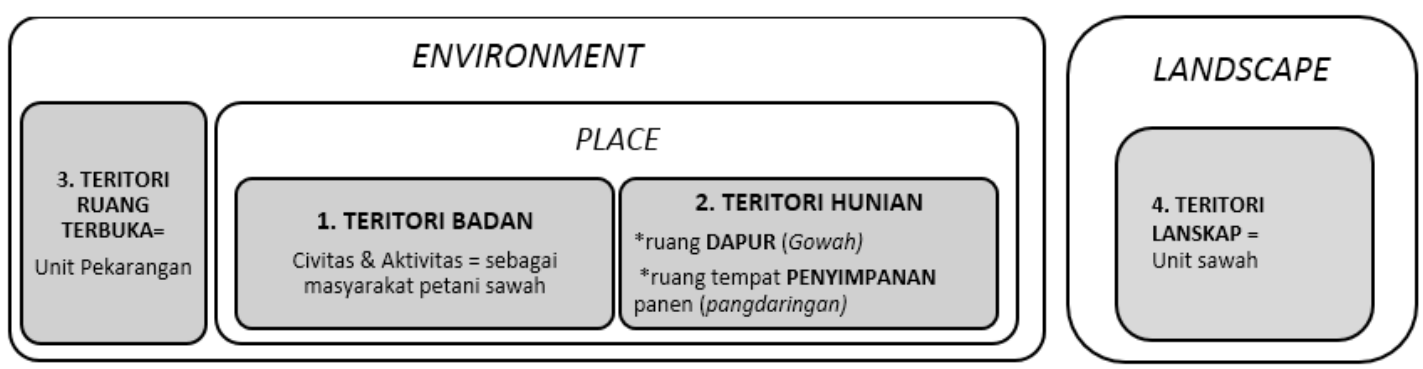

Gambar 7. Pola spasial teritori masyarakat petani sawah komunitas Ciptagelar

Sumber: (Kusdiwanggo, 2012)

\section{Kesimpulan}

Konsep pola spasial teritori lanskaphunian masyarakat peladang Desa Juruan Laok terdiri atas dua kategori utama yaitu: struktur spasial yang terdiri dari tema-tema empiris (pola hunian dan pola lanskap pertanian) dan nilai spasial yang terdiri dari tema-tema sosial (civitas, aktivitas dan artefak). Konsep spasial lanskap-hunian masyarakat peladang Desa Juruan Laok terdiri dari tiga teritori utama yaitu: teritori hunian, teritori pekarangan dan teritori lanskap pertanian. Berdasarkan teori ruang manusia (human space) dan teori ruang antropologis-arsitektur didapatkan pola spasial teritori yang disebut habitat terdiri dari tiga. Sub-topologi pertama yaitu place terdiri dari domain badan (civitas, aktivitas dan artefak) dan domain hunian. sub-topologi kedua yaitu environment (tapak) terdiri dari teritori ruang terbuka yaitu unit pekarangan (taneyan). Sedangkan konsep ketiga yaitu landscape terdiri dari teritori lanskap pertanian (ladang jagung/tegal). Ketigannya tersusun membentuk satu gelembung hirarki di mana place, berada di dalam environment; sedangkan place dan environment berada di dalam landscape. Gabungan ketiga subtipotopologis disebut sebagai habitat.

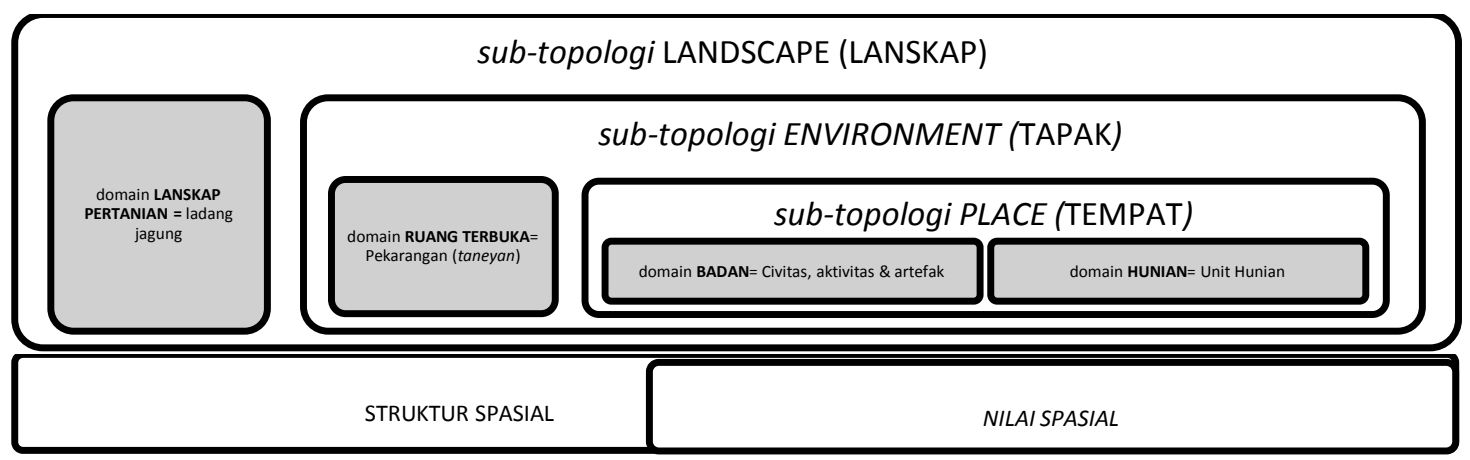

Gambar 8. Pola spasial teritori masyarakat Peladang desa Juruan Laok 


\section{Daftar Pustaka}

Amin, J. J. A., Rifai, M. A., Purnomohadi, N., \& Faisal, B. (2016). Mengenal Arsitektur Lanskap Nusantara. Yogyakarta: Pustaka Pelajar.

Ardianti, I., Antariksa, \& Wulandari, L. D. (2014). Teritorialitas Ruang Sosial Budaya Pada Permukiman Etnis Madura-Hindu Dusun Bongso Wetan Gresik. (Proseding). SEMINAR NASIONAL ARSITEKTUR PERTAHANAN (ARSHAN) 2014.

Ari, I. R. D., \& Antariksa. (2005). Studi Karakteristik Permukiman di Kecamatan Labang, Madura. Jurnal Asosiasi Sekolah Perencanaan Indonesia (ASPI), Vol.4(No.2 (April 2005)), PP.78-93.

Asikin, D., Antariksa, \& Wulandari, L. D. (2016, 8-10 Novemeber 2016). The Madurese Cultural Values in Kotalama Settlements - Malang. Paper presented at the Sriwijaya International Conference on Engineering, Science \& Technology (SICEST) 2016, Bangka IslandIndonesia.

Boelaars, J. H. M. C. (1984). Kepribadian Indonesia Modern: Suatu Penelitian Antropologi Budaya. Jakarta: Gramedia.

Bollnow, O. F. (1963 \& 2011). Human Space. translated by Christine Shuttleworth. London: Hyphen Press.

BPS. (2016). Kecamatan Batuputih Dalam Angka 2016. Sumenep: Badan Pusat Statistik Kabupaten Sumenep.

Citrayati, N., Antariksa, \& Titisari, E. Y. (2008). Permukiman Masyarakat Petani Garam Di Desa Pinggir
Papas, Kabupaten Sumenep. arsitektur e-Journal, Volume 1 Nomor 1, Maret 2008.

Cresswell, J. (2012). Eduactional Research: Planning, Conducting, and Evaluating Quantitative and Qualitative Research. Ney Jersey: Person Education, Inc.

Creswell, J. (2010). Research Design; Pendekatan Kualitatif, Kuantitatif dan Mixed. Yogyakarta: Pustaka Pelajar.

De Jonge, H. (1989). Madura dalam Empat Zaman: Pedagang, Perkembangan Ekonomi dan Islam Suatu Studi Antropologi Ekonomi. Jakarta: PT. Gramedia.

Egenter, N. ( 1992). O.F. Bollnow and the Ontology of Home and Movement Outside. Paper presented at the The Ancient Home and the Modern Internatio nalized Home: Dwelling in Scandinavia, Norway.

Fathony, B., Mulyadi, L., \& Sukowiyono, G. (2012). Konsep Spasial Permukiman Suku Madura Di Gunung Buring Malang Studi Kasus Desa Ngingit. Paper presented at the TEMU ILMIAH IPLBI 2012.

Fauzia, L., Ari, I. R. D., \& Hariyani, S. (2009). Karakteristik Permukiman Taneyan Lanjhang Di Kecamatan Labang, Madura (Studi Kasus Desa Jukong dan Desa Labang). arsitektur e-Journal, Volume 2(Nomor 1, Maret 2009), 51-65.

Febrianto, R. S., Wulandari, L. D., \& Santosa, H. (2016). Ekspresi Lanskap-Agrikultur dan Pola Permukiman Masyarakat Peladang di Madura Timur. Jurnal Ruas, Vol. 14 No 1, Juni 2016, pp. 11-23.

Geertz, C. (1983). Involusi Pertanian: Proses Perubahan Ekologi di 
Indonesia. Jakarta: Bhratara Karya Aksara.

Hartiningsih. (2008). Perubahan Sistem Spasial Rumah Tinggal Berfungsi Ganda Di Daerah Umbulharjo Yogyakarta. Jurnal Lintas Ruang, vol. 2, edisi. 2 ,2008, pp.1-9.

Hefni, M. (2008). Local Knowledge Masyarakat Madura: Sebuah Strategi Pemanfaatan Ekologi Tegal Di Madura. Jurnal Karsa, Vol. XIV No. 2 Oktober 2008, Hal.131-141.

Hillier, B. ( 1989). The Architecture of the Urban Object. Ekistics: The Problems and Science of Human Settlements, vol. 56, no 334/335. January/February-March/April 1989.

Kuntowijoyo. (2002). Perubahan Sosial dalam Masyarakat Agraris Madura 1850-1940. Yogyakarta: Mata Bangsa.

Kusdiwanggo, S. (2011, 26 Maret 2011). Aspek Gender Pada Arsitektur Lumbung. Paper presented at the Prosiding Seminar Nasional 2011 Akrab Lingkungan, Kearifan Lokal dan Kemandirian, Hotel Santika Permier Malang.

Kusdiwanggo, S. (2012). Peran dan Pengaruh Kultur Padi pada Pola Ruang-Tempat Hunian Masyarakat Ciptagelar. Paper presented at the Prosiding Seminar Nasional Riset Arsitektur dan Perencanaan: Sistem Spasial pada Seting Lingkungan Kehidupan.

Ma'arif, S. (2015). The History of Madura. Yogyakarta: Araska.

Madanipour, A. (1996). Design of Urban Space: An Inquiry into Socio-Spatial Process. Chichester: John Wiley \& Sons.

Maningtyas, R. T. (2013). Kajian Desain Lanskap Permukiman Tradisional
Madura. (Thesis), Institut Pertanian Bogor, Bogor.

Nawiyanto. (2011). Konsepsi Sosio Kultural Etnis Jawa dan Madura di Eks-Karesidenan Besuki tentang Pangan. Jurnal Humaniora, Vol 23, No 2, Hal.125-139.

Poerwandari, K. (2007). Pendekatan Kualitatif untuk Penelitian Perilaku Manusia. Depok: Lembaga Pengembangan Sarana Pengukuran dan Pendidikan Psikologi (LPSP3) Fakultas Psikologi Universitas Indonesia.

Purbadi, Y. D. (2010). Tata Suku dan Tata Spasial pada Arsitektur Permukiman Suku Dawan di Desa Kaenbaun di Pulau Timor. (Disertasi. Tidak Diterbitkan), Universitas Gadjah Mada, Yogyakarta:.

Rapoport, A. (1977). Human Aspects of Urban Form, Towards A Man Environment Aproach to Urban Form and Design. USA: Oxford University Press.

Rapoport, A. (1982). The Meaning of The Built Enviroment. California: Sage Publications.

Ridjal, A. M. (2015). Memahami Makna Ruang Melalui Simpukng. Jurnal Ruas, Vol.13 No.1 Juni 2015, pp.7584.

Rochana, T. (2012). Orang Madura: Suatu Tinjauan Antropologis. Humanus, Vol. XI No.1 Th. , Hal.4651.

Sasongko, W. (2005). Pengaruh Sistem Kekerabatan Terhadap Perubahan Tatanan Rumah Madura Perantauan Di Buring - Malang Retrieved from Universitas Brawijaya Malang:

Susanto, E. (2008). Ruh Islam Dalam "Wadag" Lokal Madura: Kasus 
"Tanean Lanjeng". Jurnal Karsa, Vol. XIV No. 2 Oktober 2008, Hal. 142-147.

Syafrudin. (2009). Pergeseran Pola Ruang Pemukiman Berbasis Budaya Lokal Di Desa Hu`u Kabupaten Dompu Ntb. (Thesis), Universitas Diponegoro Semarang, Semarang.

Syamsuddin, M. (2007). Agama, Migrasi Dan Orang Madura. Aplikasia, Jurnal Aplikasi Ilmu Agama, Vol. VIII, No.2 Desember 2007, Hal. 150-182.

Tjahjono, R., Sudikno, A., \& Wulandari, L. D. (2011). Lokalitas Ruang Hunian Masyarakat Madura Di Pedalaman Malang. Paper presented at the Seminar Nasional Ruang \& Tempat Dalam Latar Indonesia, Yogyakarta.

Tulistyantoro, L. (2005). Makna Ruang Pada Tanean Lanjang Di Madura. Jurnal Dimensi Interior, Vol. 3, No. 2, Desember Hal 137 - 152.

Wahid, A. (2015). Dari Sistem Lisensi ke Monopoli : Politik Ekonomi Garam di Indonesia Pada Masa
Kolonial. Jurnal Sejarah dan Nilai Budaya, Vol.3 No.2.

Wismantara, P. P. (2009). Politik Ruang Gender Pada Permukiman Taneyan Lanjhang Sumenep. EGALITA, Jurnal Kesetaraan dan Keadilan Gender, Vol. IV, No 2, 2009, pp: 185 - 198. doi:Pusat Studi Gender (PSG) Universitas Islam Negeri Maulana Malik Ibrahim Malang Zamroni, I. (2007). Juragan, Kiai dan Politik di Madura. Jurnal Unisia, Vol 30, No 65, Hal.264-276. 